\title{
Development of a Competitive ELISA for the Detection of a Furaltadone Marker Residue, 3-Amino-5-Morpholinomethyl-2-Oxazolidinone (AMOZ), in Cultured Fish Samples
}

\author{
Shi-Yuan SHEU ${ }^{1)}$, Yung-Te TAI ${ }^{2}$, Wen-Ren LI ${ }^{3)}$, Yi-Chih LEI ${ }^{2,4)}$, Kuan-Huei HSIEH ${ }^{2)}$, Chiu-Yueh LIN $^{2}$, \\ Chu-Chen $\mathrm{CHENG}^{2}$, Tong-Hsuan $\mathrm{CHANG}^{2)}$ and Tzong-Fu $\mathrm{KUO}^{4)^{*}}$ \\ ${ }^{1)}$ School of Chinese Medicine, China Medical University, Taichung City 404, Taiwan, ROC \\ 2) Taiwan Advance Bio-Pharmaceutical Inc., Taipei County 221, Taiwan, ROC \\ ${ }^{3)}$ Department of Chemistry, National Central University, Taoyuan County 320, Taiwan, ROC \\ 4) Department and Graduate Institute of Veterinary Medicine, National Taiwan University, Taipei City 106, Taiwan, ROC
}

(Received 16 April 2012/Accepted 6 June 2012/Published online in J-STAGE 20 June 2012)

ABSTRACT. This report describes an enzyme-linked immunosorbent assay (ELISA) for tissue-bound metabolite 3-amino-5-morpholinomethyl-2-oxazolidinone (AMOZ) and the application to residue analysis in cultured fish samples. The residue is monitored as a marker for the drug furaltadone. The assay enables the detection of protein bound AMOZ in the form of a 2-nitrophenyl derivative (2-NP-AMOZ) in sample supernatant or extract after acid hydrolysis and derivatization with $o$-nitrobenzaldehyde. Polyclonal rabbit antibodies were produced with a new immunogen hapten, 2-NP-HXA-AMOZ. The new ELISA had adequate analytical sensitivity $\left(\mathrm{IC}_{50}\right.$ value $0.325 \mu \mathrm{g}$ $\mathrm{kg}^{-1}$; limit of detection $0.1 \mu \mathrm{g} \mathrm{kg}^{-1}$ ) to determine a trace of AMOZ residue and had a high selectivity. Recoveries of AMOZ fortified at the levels of $0.1,0.5$ and $1.0 \mu \mathrm{g} \mathrm{kg}^{-1}$ ranged from 89.8 to $112.5 \%$ with coefficients of variation of $12.4-16.2 \%$ over the range of AMOZ concentrations studied. The results obtained with the ELISA correlated well with those obtained by commercial test kits for 150 tested samples $(r=0.984)$. The results suggest that the developed ELISA is a highly specific, accurate, and sensitive method suitable for high throughput screening for AMOZ residues.

KEY WORDS: 3-amino-5-morpholinomethyl-2-oxazolidinone (AMOZ), ELISA, furaltadone, nitrofurans, residue.

doi: 10.1292/jvms.12-0165; J. Vet. Med. Sci. 74(11): 1439-1446, 2012

The European Union banned the use of nitrofurans as veterinary drugs for food-producing animals, because of their potentially mutagenic, carcinogenic and teratogenic effects on human health $[1,2,23]$. The minimum required performance limit (MRPL) for nitrofurans was set at $1 \mu \mathrm{g} \mathrm{kg}^{-1}$ in poultry meat and aquaculture products by Commission Decision 2003/181/EC amending Decision 2002/657/EC [6, 7]. Previously, nitrofurans had been widely and effectively used for the prevention and treatment of gastrointestinal and dermatological infections caused by Escherichia coli, Salmonella spp., Mycoplasma spp., coliforms Coccidia spp., and some other protozoa, and as growth promoters in livestock [12].

The most common nitrofurans are furaltadone (FTD), furazolidone (FZD), nitrofurantoin (NFT) and nitrofurazone (NFZ), which all share 5-nitrofuraldehyde as a common chemical structure (Fig. 1). Various studies have demonstrated that the nitrofurans are metabolized rapidly by animals in vivo, and stable tissue-bound metabolites are formed that may be released by mild acid hydrolysis and monitored as marker residues in edible tissues [11, 21]. Accordingly, 3-amino-5-morpholinomethyl-2-oxazolidinone (AMOZ), 3-amino-2-oxazolidinone (AOZ), 1-aminohydantoin (AHD) and semicarbazide (SEM) are monitored

\footnotetext{
*Correspondence to: Kuo, T.-F., Department and Graduate Institute of Veterinary Medicine, National Taiwan University, Taipei City 106, Taiwan, ROC.

e-mail: tzongfu@ntu.edu.tw

(C)2012 The Japanese Society of Veterinary Science
}

as marker residues for the drugs furaltadone, furazolidone, nitrofurantoin and nitrofurazone, respectively.

Residues of these nitrofurans could present a potential risk for public health safety. EU member states are required to monitor compliance with the ban on nitrofurans through their annual national residues control plans. Trade restrictions arising from such findings prompted many food producers and regulatory authorities to instigate nitrofuran testing schemes. Effective surveillance for the illicit use of nitrofurans requires sensitive and specific methods to detect the analytes from treated animals. Monitoring of illegal administration of the furaltadone parent compound is currently carried out by detection of the marker residue AMOZ, which is the metabolite moiety derived from furaltadone. The residual control needs to define an analytical strategy based on the combination or not of screening and confirmatory methods. In the first screening test, which is low in cost, high-volume, and rapid, the potentially positive samples should be verified in a laboratory to ensure their accuracy. These techniques rely on expensive instruments operated by well-trained analysts and prior preparation of analytes, which is time-consuming. Various methods have been released for the determination of AMOZ in poultry, porcine, shrimp and the retina by HPLC-UV [8], LC-MS [16], and LC-MS/MS [3, 12, 19]. The detection limits of the screening and confirmatory methods are reported herein (Table 1), and the sensitivity of the immunoassay method was well below the instrumental methods in general.

Consequently, as a low cost, rapid and high-capacity screening method for sensitive nitrofuran metabolite deter- 


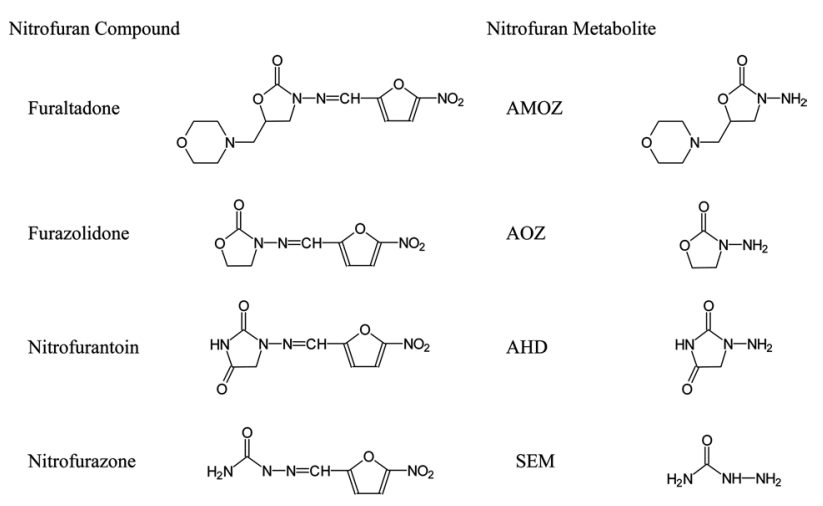

Fig. 1. Metabolites considered for the analysis of the residues of the 4 nitrofurans.

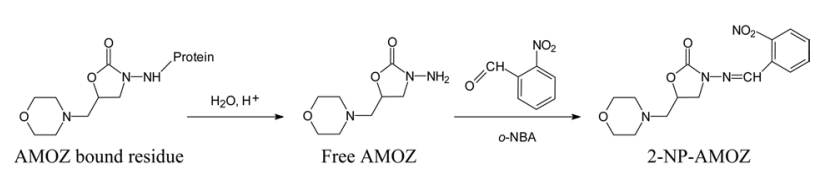

Fig. 2. Derivatizing reaction leading to the nitrophenyl derivatives of AMOZ.
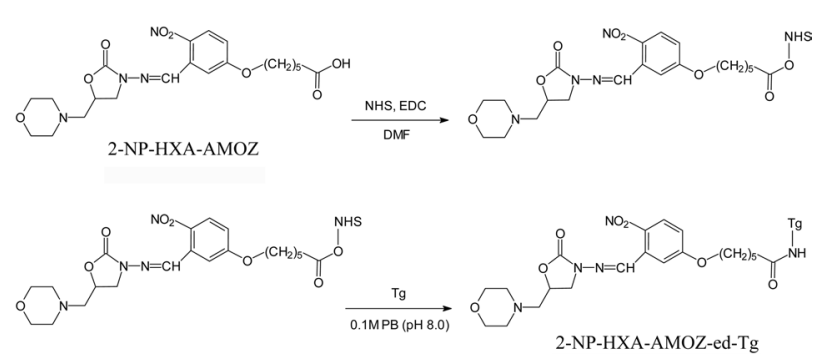

Fig. 3. Synthesis and structures of hapten derivatives for conjugation to carrier protein $\mathrm{Tg}$.

mination, the ELISA (enzyme-linked immunosorbent assay) can provide an inexpensive, sensitive and fast screening alternative for the detection of samples containing trace amounts of low-molecular weight analytes such as nitrofurans. In principle, specifically tailored or modified antibodies are capable of detecting nitrofuran metabolites through the use of an enlarge target compound, which can be formed by a simple derivatization step [5].

Recent efforts in ELISA development have led to the production of other specific antibodies for nitrofurans. ELISAs for the furazolidone metabolite $\mathrm{AOZ}$ were developed using the carboxy phenyl AOZ (CPAOZ) hapten for antibody production $[4,9,10,14]$, and were used in assays specific for porcine, beef, chicken, shrimp and fish tissue analysis. Liu et al. produced polyclonal antibodies against CPAHD that were specific to nitrofurantoin and used for in drinking water [20]. Similar approaches were undertaken for the development of the ELISA formats based on monoclonal and polyclonal antibodies against CPSEM as a metabolic target of nitrofurazone by Cooper et al. [13], Gao et al. [15] and Vass et al.
Table 1. Comparison of the detection limit with commercial nitrofuran (AMOZ) ELISA test kits and the instrumental analysis

\begin{tabular}{lccc}
\hline Method & $\begin{array}{c}\text { ELISA kit } / \\
\text { Instruments }\end{array}$ & Detection of limit & Reference \\
\hline Screening & Homemade & $0.1 \mu \mathrm{g} \mathrm{kg}^{-1}$ & \\
assay & MaxSignal $^{\mathrm{TM}}$ & $0.1 \mu \mathrm{g} \mathrm{kg}^{-1}$ & \\
& RIDASCREEN & & \\
& Charm $^{\circledR}$ & $0.2 \mu \mathrm{g} \mathrm{kg}^{-1}$ & \\
Instrumental & $0.5 \mu \mathrm{g} \mathrm{kg}^{-1}$ & \\
analysis & HPLC-UV & $10.0 \mu \mathrm{g} \mathrm{kg}^{-1}$ & {$[16]$} \\
& HPLC-UV & $2.0 \mu \mathrm{g} \mathrm{kg}^{-1}$ & {$[8]$} \\
& HPLC-UV & $2.0 \mu \mathrm{g} \mathrm{kg}^{-1}$ & {$[12]$} \\
& LC/MS & $10.0 \mu \mathrm{g} \mathrm{kg}^{-1}$ & {$[16]$} \\
& LC-MS/MS & $0.5 \mu \mathrm{g} \mathrm{kg}^{-1}$ & {$[19]$} \\
& LC-MS/MS & $0.2 \mu \mathrm{g} \mathrm{kg}^{-1}$ & {$[12]$} \\
& LC-MS/MS & $0.13 \mu \mathrm{g} \mathrm{kg}^{-1}$ & {$[3]$} \\
\hline
\end{tabular}

[24], which were considered to be effective screening assays for porcine muscle, chicken tissue and egg samples.

The first monoclonal antibodies capable of AMOZ detection were raised against a carboxy phenyl AMOZ (CPAMOZ) hapten and used in an assay specific for shrimp tissue analysis [22]. Samples of shrimp were subjected to hydrolysis, and AMOZ was derivatized with $o$-nitrobenzaldehyde ( $o$-NBA), subjected to ethyl acetate extraction and then washed in hexane prior to detection (Fig. 2). This monoclonal antibody-based ELISA provided a detection capacity for AMOZ in shrimp samples at $0.3 \mu \mathrm{g} \mathrm{kg}^{-1}$, and the resultant limit of detection (LOD) was $0.16 \mu \mathrm{g} \mathrm{kg}^{-1}$.

In this study, we report on the development of a new assay for the determination of AMOZ residues, a tissue-bound metabolite of the nitrofuran furaltadone, in cultured fish and application in a simultaneous comparison with a commercially available kit in field test screens. Novel, highly sensitive polyclonal rabbit antibodies for detecting 2-NP-AMOZ, were produced with a new immunogen hapten, 2-NP-HXAAMOZ ((6-[4-[Nitro-3-[[[2-oxo-3-(5-morpholinomethyl)oxazolidinyl]imino]methyl]]phenoxyl] hexanoic acid, $\mathrm{C}_{20} \mathrm{O}_{8} \mathrm{~N}_{4} \mathrm{H}_{28}$, FW 452)) (Fig. 3). Our work shows the advantages of good specificity, high sensitivity, and adequate reliability in high-throughput screening of AMOZ residues.

\section{MATERIALS AND METHODS}

Reagents: All chemicals were of reagent grade or better. 3-Amino-5-morpholinomethyl-2-oxazolidinone (AMOZ), 2-NP-AMOZ, 2-NP-AOZ, 2-NP-AHD and 2-NP-SEM were obtained from Fluka, Sigma-Aldrich (Tokyo, Japan). 3-Amino-2-oxazolidinone (AOZ), 1-aminohydantoin (AHD), semicarbazide (SEM), furaltadone (FTD), furazolidone (FZD), nitrofurantoin (NFT), nitrofurazone (NFZ), o-nitrobenzaldehyde (o-NBA), $N$-hydroxysuccinimide (NHS), $N(3-$ dimethylaminopropyl) $N$ '- ethylcarbodiimide hydrochloride (EDC), bovine serum albumin (BSA), ovalbumin (OVA), porcine thyroglobulin ( $\mathrm{Tg}$ ), goat anti-rabbit IgG-HRP, sodium periodate, ethylene glycol, 1,8-diaminooctane, sodium borohydride, potassium phosphate dibasic and Freund's complete/incomplete adjuvant were commercially available 
from Sigma-Aldrich (St. Louis, MO, U.S.A.). 2-NP-HXAAMOZ was provided by Professor Li Wen-Ren, Department of Chemistry, National Central University (Taoyuan, Taiwan, R.O.C.). Liquid chromatography-grade dimethyl sulfoxide (DMSO), ethyl acetate and n-hexane were purchased from TEDIA (Fairfield, OH, U.S.A.). Horseradish peroxidase (HRP) was obtained from Roche (Basel, Switzerland). TMB ready-to-use substrate was obtained from Kem-En-Tec (Taastrup, Denmark). LC grade water was purified in-house with a Milli-Q water system (Millipore, Billerica, MA, U.S.A.) for use in preparation of all solutions.

Instrumentation and supplies: Microtiter plates with 96 wells were obtained from Costar (Cambridge, MA, U.S.A.). The antibody was dispensed in microtiter plates using a $\mu$ Fill microplate dispenser (Bio-Tek, Winooski, VT, U.S.A.), and the microtiter plates were washed with the washing solution to remove unbound antibodies using a $96 \mathrm{PW}$ microplate washer (Tecan, SLT, Salzburg, Austria). The absorbances of each well were measured with an EMax microplate reader (Molecular Devices, Sunnyvale, CA, U.S.A.). A high-speed refrigerated centrifuge and a tabletop centrifuge (Kubota 6900 and 5400, Tokyo, Japan) were used. The organic extracts were evaporated under a stream of nitrogen in a TurboVap LV evaporator (Caliper Life Sciences, Hopkinton, MA, U.S.A.).

AMOZ hapten derivatives for conjugation with proteins: 2-NP-HXA-AMOZ was covalently attached to OVA and $\mathrm{Tg}$ to be used as the immunogen or BSA to be used as the coating antigen by the active ester method. The pale yellow powder, the AMOZ hapten derivative depicted in Fig. 3, was reacted with NHS to obtain active esters, and the isolated esters were then reacted with proteins. In this procedure, $15 \mathrm{mg}$ of NHS $(130 \mu \mathrm{mol})$ and $30 \mathrm{mg}$ of EDC $(156 \mu \mathrm{mol})$ were added sequentially to a solution of $20 \mathrm{mg}$ of 2-NP-HXA-AMOZ ( $44 \mu \mathrm{mol}$ ) dissolved in $2 \mathrm{~m} l$ dry DMF. The activated hapten derivative was then gently stirred at room temperature for $1 \mathrm{hr}$. Then, $420 \mu \mathrm{l}$ activated hapten derivative was added dropwise to OVA solution $(20 \mathrm{mg}$ in $4 \mathrm{~m} l$ of $0.1 \mathrm{~N}$ phosphate buffer at $\mathrm{pH} 8.0$ ) by selecting a protein/hapten molar ratio equal to 1:20 (OVA/hapten); 135 $\mu l$ activated hapten derivative was then added dropwise to Tg solution $(20 \mathrm{mg}$ in $4 \mathrm{~m} l$ of $0.1 \mathrm{~N}$ phosphate buffer at $\mathrm{pH}$ 8.0 ) by selecting a protein/hapten molar ratio equal to $1: 100$ (Tg/hapten). The resultant solutions were stirred for $1 \mathrm{hr}$ at room temperature, and the conjugates were then dialyzed against 3 liters of PBS (10 mM phosphate, $140 \mathrm{mM} \mathrm{NaCl}$, $2.7 \mathrm{mM} \mathrm{KCl}, \mathrm{pH} 7.4$ ) overnight at $4^{\circ} \mathrm{C}$ with two changes of buffer. The dialyzed solution of immunogen was frozen at $-20^{\circ} \mathrm{C}$ until use. The coating antigen conjugate was prepared by conjugation of the activated hapten derivative with BSA as described above (270 $\mu l$ activated hapten derivative and selecting a BSA/hapten molar ratio equal to 1:20).

Hapten-HRP tracer: A two-step, general synthesis of AMOZ-ed-HRP conjugates was performed. The first phase of the synthesis involved the preparation of octanediaminemodified HRP: $2 \mathrm{mg}$ of HRP was dissolved in $0.2 \mathrm{ml}$ of a $5 \mathrm{mM}$ sodium acetate buffer, $\mathrm{pH} 4.5$, and then $20 \mu l$ of a freshly prepared $46.8 \mathrm{mM}$ solution of sodium periodate in
Milli-Q water was added. The color rapidly changed from brown to green. This solution was incubated for $30 \mathrm{~min}$ at room temperature in the dark. Two microliters of ethylene glycol was added to stop the reaction. After an additional incubation for $15 \mathrm{~min}$, the reaction mixture, $100 \mu l$ of 1,8-diaminooctane solution $(0.35 \mathrm{M}$, dissolved in $1 \mathrm{~N} \mathrm{HCl}, \mathrm{pH}$ adjusted to 2.5), and $300 \mu l$ of Milli-Q water were added and mixed. Subsequently, this mixture was adjusted to $\mathrm{pH}$ 9.5 with sodium carbonate solution and was allowed to react for $1.5 \mathrm{hr}$ at room temperature in the dark. Finally, $32 \mu \mathrm{l}$ of a freshly prepared $0.26 \mathrm{M}$ solution of sodium borohydride in Milli-Q water was added, mixed, and reacted for $1 \mathrm{hr}$ at room temperature in the dark. The resultant HRP solution was then dialyzed against 5 liters of PBS overnight at $4^{\circ} \mathrm{C}$ with two changes of buffer.

The second step of the synthesis was the preparation of AMOZ-ed-HRP conjugates: $2 \mathrm{mg}$ of 2-NP-HXA-AMOZ $(4.4 \mu \mathrm{mol}), 2 \mathrm{mg}$ of NHS (17.4 $\mu \mathrm{mol})$ and $4 \mathrm{mg}$ of EDC $(20.9 \mu \mathrm{mol})$ were dissolved in dry DMF $(1 \mathrm{~m} /)$. The mixture was gently stirred at room temperature for $3 \mathrm{hr}$. The activated hapten was added while stirring to the dialyzed HRP in phosphate buffer to obtain a molar ratio 10:1 (hapten/HRP). The conjugation mixture was stirred at room temperature for $1.5 \mathrm{hr}$, and the formed product was purified and concentrated using a Centriprep-30 unit (Amicon) having an MWCO of 30000 . The tracer obtained was diluted with an equal volume of glycerol and kept at $-20^{\circ} \mathrm{C}$ until use.

Polyclonal antibodies preparation: Two groups of New Zealand white rabbits weighing $2-2.5 \mathrm{~kg}$ (in duplicate) were immunized by multiple-site injection with 2-NP-HXAAMOZ-ed-OVA and 2-NP-HXA-AMOZ-ed-Tg. All experimental procedures were approved by the Institutional Animal Ethics Committee of National Taiwan University, and conducted in accordance with the internationally accepted principles for laboratory animal use and care. Immunogen emulsions were prepared by repeatedly passing this mixture through a narrow-bored cylindrical Pyrex block, drilled at each end to accommodate 2 syringes. The first immunizations were composed of $500 \mu \mathrm{l}$ of PBS containing $1 \mathrm{mg}$ of immunogen emulsified in $500 \mu \mathrm{l}$ of Freund's complete adjuvant. Subsequent immunizations, at $3-5$-week intervals, were of the same volume, with complete adjuvant replaced by incomplete adjuvant. Blood samples were taken from the ear vein at 3-5-week intervals to follow the apparition of the antibodies.

Practically, AMOZ was detected in the derivatized form of 2-NP-AMOZ; the competitive ELISA format described was used to determine the sensitivity and specificity for free 2-NP-AMOZ of test bleeds of the polyclonal antisera. Therefore, the sera were checked for their titer and ability to compete with 2-NP-AMOZ. The titer check was done in an indirect ELISA format, using 2-NP-HXA-AMOZed-BSA as the coating antigen $(10 \mu \mathrm{g} / \mathrm{m} l)$ and rabbit sera $(1: 1,500-1: 25,000)$ as the primary antibody. The specificity test was performed in an indirect competitive ELISA format as described, and the antiserum shown to have the strongest competition toward 2-NP-AMOZ was selected for further purification. 
Evaluations of antibody sensitivity: The optimum antiserum was determined by checkerboard titration. Standard solutions of 2-NP-AMOZ were prepared serially, and spiked concentrations of $0.01,0.03,0.1,0.3,1,3$ and $10 \mu \mathrm{g} \mathrm{kg}^{-1}$ were used for obtaining standard curves. Assays were performed according to the indirect ELISA, and the midpoint of each displacement standard curve was calculated in order to determine its $\mathrm{IC}_{50}$. The $\mathrm{IC}_{50}$ was defined as the concentration of inhibitor required to inhibit color development by $50 \%$ compared to control wells containing no competitors. The highly sensitive and specific polyclonal antibody was selected, purified by affinity chromatography on a Protein ASepharose column (GE Healthcare) and concentrated using a Centriprep-50 unit (Amicon) having an MWCO of 50000. The protein concentration of AMOZ-specific antibodies was determined by a Bio-Rad Protein Assay (Bio-Rad Laboratories).

AMOZ ELISA development: Optimal concentrations/dilutions of the antibody adsorbed to the plate, enzyme conjugate, and substrate solution were determined through checkerboard titrations of each reagent against all other reagents, following confirmation of the best choice of reaction vessels (Costar Catalog \#2592). The ELISA was carried out using the methodology described previously [18]. One hundred microliters of anti-AMOZ polyclonal antibody $(2.5 \mu \mathrm{g} / \mathrm{ml})$ in a coating buffer $(50 \mathrm{mM}$ carbonate/bicarbonate buffer, $\mathrm{pH}$ 9.6) was added to each well of a split-type microtiter plate (12 strips of 8 wells each) with a $\mu$ Fill microplate dispenser (Bio-Tek), and incubation was performed overnight at $4^{\circ} \mathrm{C}$. The plate was then washed with washing buffer (PBS with $0.05 \%$ Tween 20, PBST) 3 times using a 96-well ELISA plate washer (Tecan). After washing, the wells were treated with $200 \mu l$ of $0.1 \%$ nonfat dried milk powder in PBS for 2 $\mathrm{hr}$ at room temperature. After $2 \mathrm{hr}$ of incubation, the microtiter plates were dried at $20^{\circ} \mathrm{C}$ with $25 \% \mathrm{RH}$ for $4 \mathrm{hr}$. All the 96-well plates were then placed into resealable plastic bags with desiccant and stored until use $\left(4^{\circ} \mathrm{C}\right)$.

The quantitative ELISA kit for nitrofuran metabolite AMOZ consists of a 96-well microtiter plate coated with an anti-AMOZ polyclonal antibody, six 2-NP-AMOZ standards $\left(0,0.05,0.1,0.25,0.5\right.$, and $\left.1 \mu \mathrm{g} \mathrm{kg}^{-1}\right), 100 \times$ conc. horseradish peroxidase (HRP)-labeled conjugate, a derivative reagent (10 $\mathrm{mM} o$-NBA in DMSO) and a substrate solution (3,3',5,5'-tetramethylbenzidine; TMB), extraction buffer, washing buffer, and stop solution $(0.5 \mathrm{~N} \mathrm{HCl})$.

Fish sample preparation prior to measurement: Fish samples were purchased from local fish markets and included Micropterus salmoides(California bass), Oreochromis sp. (Taiwan tilapia), Chanos chanos(Milkfish), and Anguilla japonica(eel). Before being analyzed, the fish was filleted, the skin and bones were removed, and the muscles were minced and frozen. When samples were thawed and homogenized, aliquots $(1.0 \mathrm{~g})$ were fortified with the following AMOZ derivatization and extraction procedure (when required): $\mathrm{H}_{2} \mathrm{O}(4 \mathrm{~m} l), 1 \mathrm{~N} \mathrm{HCl}(0.5 \mathrm{ml})$ and $100 \mu l$ of $10 \mathrm{mM} o$-NBA (in DMSO) were added to the homogenate, the mixture was vortexed for $60 \mathrm{sec}$ and then incubated overnight at $37^{\circ} \mathrm{C}$ (approximately $16 \mathrm{hr}$ ). After cooling to room temperature,
$0.1 \mathrm{M} \mathrm{K}_{2} \mathrm{HPO}_{4}(5 \mathrm{~m} l), 1 \mathrm{~N} \mathrm{NaOH}(0.4 \mathrm{~m} l)$ and ethyl acetate $(5 \mathrm{~m} l)$ were added to the sample, shaken vigorously (30 $\mathrm{sec})$ and centrifuged (3,000 rpm, $10 \mathrm{~min})$. The upper ethyl acetate layer $(2 \mathrm{ml})$ was transferred into glass tubes, and the extract was evaporated by heating to dryness at $50^{\circ} \mathrm{C}$ using a TurboVap evaporator system (Caliper). Hexane $(0.8 \mathrm{~m} l)$ was added to the evaporated sample and vortexed thoroughly followed by the addition of PBST $(0.8 \mathrm{~m} l)$. After vortexing again $(60 \mathrm{sec})$, samples were centrifuged $(3,000 \mathrm{rpm}, 10$ min), and then the upper hexane layer was discarded. The remaining extract was used for ELISA determination. The measured data were corrected by a dilution factor of 2 .

ELISA methodology: All reagents of the test kit were supplied ready and with the required number of strips to reach room temperature prior to use. Fifty microliters of standard $\left(0,0.05,0.1,0.25,0.5\right.$, and $1 \mu \mathrm{g} \mathrm{kg}^{-1} 2$-NP-AMOZ) or sample with $100 \mu l$ of AMOZ-horseradish peroxidase enzyme conjugate was applied to each well. Maximum binding was assessed by adding no inhibitor (zero standards) to the relevant wells. Plates were incubated for $30 \mathrm{~min}$ at room temperature $\left(19-25^{\circ} \mathrm{C}\right)$ in the dark, and the wells were then manually washed 3 times with the washing buffer ( 250 $\mu l$ per well). After washing, the plates were inverted onto absorbent paper. Substrate solution (100 $\mu l$ per well) was added, and the contents were mixed thoroughly. After 20 min, the enzymatic reaction was stopped by addition of the stop solution (100 $\mu \mathrm{l}$ per well). Absorbance was measured at $450 \mathrm{~nm}$. AMOZ concentration values were calculated by interpolation from the calibration curve, where the bound enzyme activity, expressed as the logit of the ratio (in present) between the AMOZ signal at each concentration of AMOZ $(B)$ and the bound activity in the absence of unlabeled AMOZ $\left(B_{0}\right)$ was plotted against the log of the AMOZ concentrations. The percent binding $(B / B 0 \%)$ was calculated by the following equation:

$B / B_{0 \%}=(\mathrm{OD}$ standard or sample/OD blank $) \times 100 \%$

Mathematical fitting of the curve allows evaluation of the slope of the curve, representing the sensitivity, and the response at $50 \%$ bound (mid-range of the curve), representing the specificity.

ELISA performance and characteristics: Spiked concentrations of $0.05,0.1,0.25,0.5$, and $1 \mu \mathrm{g} \mathrm{kg}^{-1} 2$-NP-AMOZ in PBST were used for obtaining standard curves, and expressed as underivatized AMOZ. The limit of detection (LOD) was based on 20 blank samples accepting no falsepositive rates (average $+3 \mathrm{SD}$ ). Twenty different Anguilla japonica(eel) samples were purchased in local retail outlets. No measurable AMOZ residues were observed by previous ELISA determinations, which proved the samples to be free of AMOZ and other nitrofuran metabolites using LC-MS. ELISA repeatability was accomplished by evaluating results from replicates of the dilution buffer (PBST) in each plate (intra-plate variation), and the inter-plate variation using the same buffers run in different plates within a run and between runs of the assay. Three-to-four replicates of each sample run on at least 5 plates on 5 separate occasions are sufficient to provide preliminary estimates of repeatability [17]. Accuracy can be assessed by inclusion of one or more 
standards in each run of the assay. The precision of the assay was assessed by measurement of the AMOZ concentration of replicate standards containing $0.1 \mu \mathrm{g} \mathrm{kg}^{-1}, 0.5 \mu \mathrm{g} \mathrm{kg}^{-1}$ and $1.0 \mu \mathrm{g} \mathrm{kg}^{-1}$. Analytical sensitivity of the assay was assessed by the smallest detectable amount of the analyte, and the analytical specificity was the degree to which the assay did not cross-react with other analytes. On the other hand, metabolites of furaltadone are known to bind covalently to cellular protein in vivo. It had been demonstrated that a proportion of the bound metabolites possess an intact side chain (AMOZ), which may be cleaved under acidic conditions and derivatized with $o$-NBA to form 2-NP-AMOZ (Fig. 2). Accordingly, AMOZ was detected in the derivatized form of 2-NP-AMOZ. Recovery was investigated by adding increasing amounts of $\operatorname{AMOZ}\left(0.1,0.5\right.$ and $\left.1.0 \mu \mathrm{g} \mathrm{kg}^{-1}\right)$ to blank fish samples, which had previously been proven to be free of contaminants. The recovery values were calculated from the formula

Recovery $\%=$ Conc. measured/Conc. fortified $\times 100 \%$

Spike preparation for cross-reactivity studies: Specificity of the assay was estimated by measuring percent cross-reactivities $(\mathrm{CR} \%)$, determined by measuring their $\mathrm{IC}_{50}$ values using the midpoint of the 2-NP-AMOZ standard curve. Competitors, the analytical standard solutions of 2-NPAMOZ, AMOZ, FTD, 2-NP-AOZ, AOZ, FZD, 2-NP-AHD, AHD, NFT, 2-NP-SEM, SEM, NFZ, derivatization reagent $(o$-NBA), antibiotics (CAP, TAP, Tc, cTc) and sulfonamides (SQX, SMT, SDM, SDZ, SMM, SMZ, SMP, ST), were used to prepare spikes for the analysis of kit selectivity. All fortified samples were made from $100 \mathrm{mg} \mathrm{kg}^{-1}$ working stock solutions prepared in distilled water. The cross-reactivity values were determined from the formula

$\mathrm{CR} \%=\left(\mathrm{IC}_{50}\right.$ 2-NP-AMOZ/IC 50 structural analogue $) \times 100 \%$

Comparison of two immunoassays for AMOZ residues: Samples were taken, and comparative in-house trials were carried out on 2 AMOZ test kits. The performance of the home-made ELISA was compared with a commercial test; a competitive enzyme immunoassay (RIDASCREEN ${ }^{\circledR}$, R-Biopharm, GmbH, Germany) was used for the analysis of nitrofuran (AMOZ, Art. No. 3711). A total of 150 fish samples, including Micropterus salmoides (California bass), Oreochromis sp. (Taiwan tilapia), Chanos chanos (Milkfish), and Anguilla japonica (eel), were incurred materials containing none or more residues of nitrofuran metabolites. The samples were also analyzed by ELISA following fortification with AMOZ at different false-positive rates in order to calculate the recovery values. Selection of a cut-off value allows classification of test results into positive or negatives categories. Comparative testing of 150 fish samples with RIDASCREEN $^{\circledR}$ (No. 3711) was carried out by associating the positive/negative categorical data. Correlation between the two methods was also obtained when the values were correlated within the positive concentration range.

\section{RESULTS}

Characterization of AMOZ polyclonal antibodies: Anibody-based assays can offer considerable simplification of the analytical procedure, if antibodies of the desired quality are incorporated into a detection system. Figure 3 shows the hapten-protein conjugates (immunogens) used in this laboratory for preparation of rabbit antibodies against tissue-bound nitrofuran metabolites. Functional rabbit antibodies were prepared when AMOZ was enlarged; this reagent mimicked the $o$-NBA agent by reaction with hexanoic acid ethyl ester. The antibodies formed enable the establishment of a competitive ELISA. Our efforts were focused on direct ELISA based on the most sensitive antibody, BW19-Tg conjugate, which was selected for further characterization with regards to sensitivity and specificity and was purified from polyclonal antisera BW19 using a Protein A-Sepharose column.

Performance characteristics of the ELISA: It is important to perform the minimum verification experiments to confirm that the new assay is acceptable for routine use in the laboratory for residue screening.

a. Repeatability and reproducibility. According to the Office International des Epizooties (OIE) guidelines, the values of controls should fall within predetermined limits (e.g., within an appropriate multiple of the standard deviation of the mean of each control) [17]. A plate dispenser (Bio-Tek) and plate washer (Tecan) were used throughout ELISA development, and preliminary evidence of repeatability (agreement between replicates within and between runs of the assay) was necessary to warrant further development of the assay format. Repeatability and reproducibility of the method were accomplished by evaluating results from replicates of the dilution buffer (PBST) in each plate (intraplate variation), and inter-plate variation using the same buffers. Based on raw absorbance values, there was a high repeatability within a plate $\left(\mathrm{OD}_{\mathrm{ave}}\right.$ around $2.125-2.251$ and $\mathrm{CV}<5.3 \%$ ) and a high level of reproducibility between plates (six batches of them) $\left(\mathrm{OD}_{\text {ave }} 2.182\right.$ and $\left.\mathrm{CV}<4.8 \%\right)$.

b. Specificity. The analytical specificity is the ability of an assay to exclusively identify a target analyte rather than a similar but different analyte in a specimen. With this approach, the specificity of the polyclonal antibody AMTg0310 in optimized assays was tested by the measurement of cross-reactivity using 2-NP-AMOZ and related compounds as described. Table 2 shows all candidate cross-reacting compounds examined. The results with 2-NP-AMOZ were selected to be used as the $100 \%$ cross-reactivity values and showed negligible cross-reactivity with other nitrofuran antibacterials, their metabolites and corresponding nitrophenyl derivatives, derivatizing agents, related antibiotics and sulfonamides, etc. The negligible assay response to $o$-NBA $(\mathrm{CR}<0.1 \%)$ eliminates the need for separation of this reagent from the sample homogenate after derivatization.

c. Analytical sensitivity. The typical AMOZ standard curve obtained using the direct ELISA method is presented in Fig. 4. The linear detection range (the concentration corresponding to $27 \%$ to $85 \%$ inhibition of binding) was 0.05 to $1.0 \mu \mathrm{g} \mathrm{kg}^{-1}$. The $\mathrm{IC}_{50}$ (concentration causing $50 \%$ inhibition of binding) was $0.325 \mu \mathrm{g} \mathrm{kg}^{-1}$, and the limit of detection (the concentration causing 90\% inhibition of binding) was $0.045 \mu \mathrm{g} \mathrm{kg}^{-1}$. According to the test preparation results, the sensitivity of the assay was evaluated by examining fish tis- 
Table 2. Cross-reactivities among 2-NP-AMOZ and related compounds of interest in direct ELISA

\begin{tabular}{lc}
\hline Competitor & Cross-reactivity ${ }^{\text {a) }}(\%)$ \\
\hline 2-NP-AMOZ & 100 \\
2-NP-AOZ & 0.2 \\
2-NP-AHD, 2-NP-SEM & $<0.1$ \\
AOZ, AMOZ, AHD, SEM & $<0.1$ \\
$o$-NBA & $<0.1$ \\
FTD, FZD, NFT, NFZ & $<0.1$ \\
Antibiotics: CAP, TAP, Tc, cTc & $<0.1$ \\
Sulfonamides: SQX, SMT, SDM, SDZ, & $<0.1$ \\
\multicolumn{1}{c}{ SMM, SMZ, SMP, ST } & \\
\hline
\end{tabular}

a) Cross-reactivity $(\%)=\left(\mathrm{IC}_{50}\right.$ of $2-\mathrm{NP}-\mathrm{AMOZ} / \mathrm{IC}_{50}$ of competitor $) \times$ $100 \%$. Abbreviations used: CAP, chloramphenicol; TAP, thiamphenicol; Tc, tetracycline; cTc, chlortetracycline; SQX, sulfaquinoxaline; SMT, sulfamethazine; SDM, sulfadimethoxine; SDZ, sulfadiazine; SMM, sulfamonomethoxine; SMZ, sulfamethoxazole; SMP, sulfamethoxypyridazine; ST, sulfathiozole.

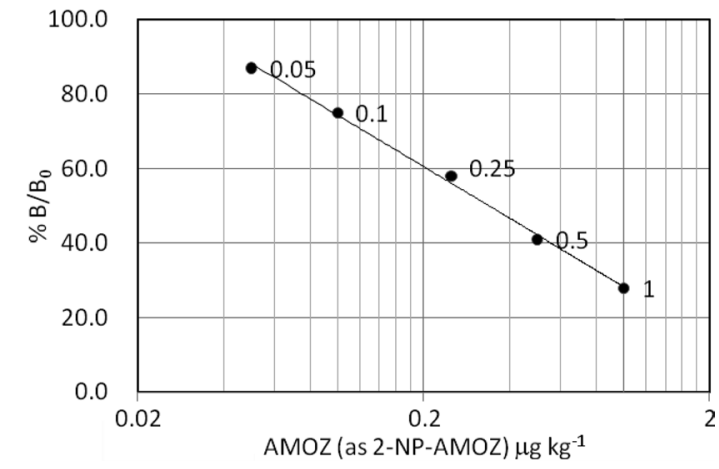

Fig. 4. Calibration curve for $\mathrm{AMOZ}$ direct ELISA. $B=$ absorbance of each standard or sample, $B 0=$ absorbance of standard $=$ control.

sue samples, and the detection limit of this assay was 0.1 $\mu \mathrm{g} \mathrm{kg}^{-1}$, which was well below the minimum required performance limits for tissue-bound residues of AMOZ at $1 \mu \mathrm{g}$ $\mathrm{kg}^{-1}$ according to the European Commission.

d. Quality assurance of ELISA. Precision: Precision is a measure of dispersion of results for a repeatedly tested sample; repeatability in an immunoassay includes the amount of agreement between replicates of each sample within a run of the assay and the amount of between run agreements for each fortified sample. The precision of the assay was assessed by measurement of the AMOZ concentration of replicate standards of $0.1 \mu \mathrm{g} \mathrm{kg}^{-1}, 0.5 \mu \mathrm{g} \mathrm{kg}^{-1}$ and $1.0 \mu \mathrm{g} \mathrm{kg}^{-1}$. The obtained mean values \pm SD and CV (\%) from replicate analyses ( $n=12$ and 24, respectively) in the same run (intraassay) and in separate runs (inter-assay) are reported in Table 3. The CV\% values were below $15.4 \%$, demonstrating an acceptable level of precision.

Accuracy: Recovery studies were performed to assess the accuracy of the direct ELISA. Blank fish samples were fortified with three different amounts of AMOZ $(0.1,0.5$ and $1.0 \mu \mathrm{g} \mathrm{kg}^{-1}$ ), which may be cleaved under acidic conditions and derivatized with $o$-NBA to form 2-NP-AMOZ. The pro-
Table 3. Intra- and interassay variations of direct ELISA spiked with 2-NP-AMOZ at three concentrations

\begin{tabular}{ccc}
\hline $\begin{array}{c}\text { Fortified conc. } \\
\left(\mu \mathrm{g} \mathrm{kg}^{-1}\right)\end{array}$ & $\begin{array}{c}\text { Mean } \\
\left(\mu \mathrm{g} \mathrm{kg}^{-1}\right)\end{array}$ & $\mathrm{CV}^{\mathrm{b})}(\%)$ \\
\hline \multicolumn{3}{l}{ Intra-assay (12 replicates) } \\
0.10 & $0.11 \pm 0.014$ & 12.8 \\
0.50 & $0.54 \pm 0.047$ & 8.7 \\
1.00 & $1.05 \pm 0.073$ & 7.0 \\
\hline \multicolumn{3}{l}{ Interassay (24 replicates: 4 replicates on 6 plates) } \\
0.10 & $0.11 \pm 0.017$ & 15.4 \\
0.50 & $0.55 \pm 0.063$ & 11.5 \\
1.00 & $1.05 \pm 0.095$ & 9.1 \\
\hline
\end{tabular}

a) $\mathrm{AMOZ}$ (as 2-NP-AMOZ) concentration found. b) Coefficient of variation.

Table 4. Recovery values obtained in fish samples for the determination of AMOZ by direct ELISA $(n=3)$

\begin{tabular}{ccc}
\hline $\begin{array}{c}\text { Fortified conc. } \\
\left(\mu \mathrm{g} \mathrm{kg}^{-1}\right)\end{array}$ & $\begin{array}{c}\text { Recovered conc. } \\
\left(\mu \mathrm{g} \mathrm{kg}^{-1}\right)\end{array}$ & Recovery $(\%)$ \\
\hline 0.10 & $0.11 \pm 0.015$ & 112.5 \\
0.50 & $0.51 \pm 0.083$ & 102.7 \\
1.00 & $0.90 \pm 0.112$ & 89.8 \\
\hline
\end{tabular}

Table 5. Comparison of AMOZ concentrations determined by the established and commercial test kits in cultured fish samples $(n=150)$

\begin{tabular}{|c|c|c|}
\hline Homemade ELISA & RIDASCREEN® No. 3711 & \\
\hline $\begin{array}{l}\text { Cutoff concentration } \\
\qquad\left(0.3 \mu \mathrm{g} \mathrm{kg}^{-1}\right)\end{array}$ & $\begin{array}{l}\text { Cutoff concentration } \\
\qquad\left(0.3 \mu \mathrm{g} \mathrm{kg}^{-1}\right)\end{array}$ & No. of samples \\
\hline+ a) & + a) & 25 \\
\hline- b) & + a) & 0 \\
\hline+ a) & - b) & 0 \\
\hline- b) & - b) & 125 \\
\hline
\end{tabular}

a) Positive test result. b) Negative test result.

posed method proved accurate, with a recovery percentage of 89.8 to $112.5 \%$ (Table 4 ), and was successfully applied to real sample analysis.

Comparison of the established ELISA and reference test kits: In the present study, the concentrations of AMOZ in fish samples were determined and used according to the manufacturer's instructions. A total of 150 cultured fish were collected from local meat markets and analyzed for residues of furaltadone by the established polyclonal ELISA and commercial RIDASCREEN ${ }^{\circledR}$ test kits. On the basis of predetermined cut-off concentrations $\left(0.3 \mu \mathrm{g} \mathrm{kg}^{-1}\right)$, the numbers of positive and negative test results are presented in Table 5; 25 samples were positive, and 125 were negative. The results of tests on 25 naturally contaminated fish samples were classified as positive; a very good correlation between the two ELISA results within the concentration range of 0.32 $-14.74 \mu \mathrm{g} \mathrm{kg}^{-1}$ was found (Fig. 5). The regression equation, $y=1.3019-0.7573 x(r=0.984, n=25)$, for these samples was calculated. Based on these results, the established ELISA and RIDASCREEN ${ }^{\circledR}$ assays performed similarly.

As indicated in Table 1, the developed ELISA for the 


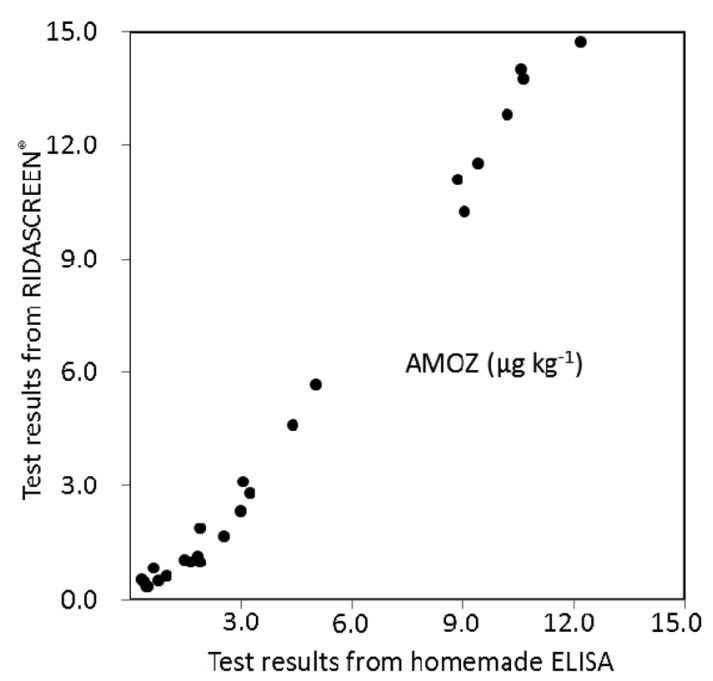

Fig. 5. Correlation between 25 naturally contaminated fish samples measured by two ELISAs.

determination of tissue-bound nitrofuran metabolites in foods of animal origin was found to be more sensitive than other commercial kits. The method was validated according to criteria set down by Commission Decision 2002/657/EC for the performance and validation of analytical methods for chemical residues. The detection capability, set on the basis of acceptance of no false-negative results, was $0.1 \mu \mathrm{g} \mathrm{kg}^{-1}$ for fish samples. This sensitivity was well below the MRPLs for tissue-bound residues of AMOZ at $1 \mu \mathrm{g} \mathrm{kg}^{-1}$ in the European Community. Additionally, comparison between the commercial RIDASCREEN $^{\circledR}$ kit and the established ELISA results indicated a relatively good correlation between the techniques.

\section{DISCUSSION}

This is an original experiment that applied a new immunoassay for routine examination for extensive monitoring and screening programs for the residues of the tissue-bound metabolite 3-Amino-5-morpholinomethyl-2-oxazolidinone (AMOZ) in 150 fish samples and compared it with a commercial kit in field test screens. The polyclonal rabbit antibodies were produced with a new immunogen hapten, 2-NPHXA-AMOZ. According to the test preparation results, the detection limit was $0.1 \mu \mathrm{g} \mathrm{kg}^{-1}$, which was much lower than the MRPLs for tissue-bound residues of AMOZ at $1 \mu \mathrm{g} \mathrm{kg}^{-1}$ in the European Community.

The results presented in this study suggest that the established ELISA can be used for screening in food animal production for AMOZ residues and can provide a sufficiently sensitivity and a high level of reproducibility, showing appreciable accuracy and precision and simultaneously giving no false-negative results. The antibody upon which this ELISA is based has now been incorporated into a commercially available ELISA test kit for AMOZ manufactured by Taiwan Advance Bio-Pharmaceutical Inc., Taiwan.
ACKNOWLEDGMENT. The authors acknowledge the financial support of the Council of Agriculture, Executive Yuan, ROC, for projects 94AS-14.2.2-FA-F2 and 95AS14.2.2-FA-F1.

\section{REFERENCES}

1. Ali, B. H. 1999. Pharmacological, therapeutic and toxicological properties of furazolidone: some recent research. Vet. Res. Commun. 23: 343-360. [Medline] [CrossRef]

2. Auro, A., Sumano, H., Ocampo, L. and Barragan, A. 2004. Evaluation of the carcinogenic effects of furazolidone and its metabolites in two fish species. Pharmacogenomics J. 4: 24-28. [Medline] [CrossRef]

3. Bock, C., Gowik, P. and Stachel, C. 2007. Matrix-comprehensive in-house validation and robustness check of a confirmatory method for the determination of four nitrofuran metabolites in poultry muscle and shrimp by LC-MS/MS. J. Chromatogr. B Analyt. Technol. Biomed. Life Sci. 856: 178-189. [Medline] [CrossRef]

4. Chang, C., Peng, D. P., Wu, J. E., Wang, Y. L. and Yuan, Z. H. 2008. Development of an indirect competitive ELISA for the detection of furazolidone marker residue in animal edible tissues. J. Agric. Food Chem. 56: 1525-1531. [Medline] [CrossRef]

5. Cheng, C. C., Hsieh, K. H., Lei, Y. C., Tai, Y. T., Chang, T. H., Sheu, S. Y., Li, W. R. and Kuo, T. F. 2009. Development and residue screening of the furazolidone metabolite, 3-amino2-oxazolidinone (AOZ), in cultured fish by an enzyme-linked immunosorbent assay. J. Agric. Food Chem. 57: 5687-5692. [Medline] [CrossRef]

6. Commission Decision 2002/657/EC. Decision of 12 August 2002 implementing Council Directive 96/23/EC concerning the performance of analytical methods and the interpretation of results. Off. J. Eur. Comm. L221: 8 - 36.

7. Commission Decision 2003/181/EC. Decision of 13 March 2003 amending Decision 2002/657/ECa as regards the setting of minimum required performance limits (MRPLs) for certain residues in food of animal origin. Off. J. Eur. Comm. L71: $17-18$.

8. Conneely, A., Nugent, A., O'Keeffe, M., Mulder, P. P. J., van Rhijn, J. A., Kovacsics, L., Fodor, A., McCracken, R. J. and Kennedy, D. G. 2003. Isolation of bound residues of nitrofuran drugs from tissue by solid-phase extraction with determination by liquid chromatography with UV and tandem mass spectrometric detection. Anal. Chim. Acta 483: 91-98. [CrossRef]

9. Cooper, K. M., Caddell, A., Elliott, C. T. and Kennedy, D. G. 2004a. Production and characterisation of polyclonal antibodies to a derivative of 3-amino-2-oxazolidinone, a metabolite of the nitrofuran furazolidone. Anal. Chim. Acta 520: 79-86. [CrossRef]

10. Cooper, K. M., Elliott, C. T. and Kennedy, D. G. 2004b. Detection of 3-amino-2-oxazolidinone (AOZ), a tissue-bound metabolite of the nitrofuran furazolidone, in prawn tissue by enzyme immunoassay. Food Addit. Contam. 21: 841-848. [Medline] [CrossRef]

11. Cooper, K. M. and Kennedy, D. G. 2005a. Nitrofuran antibiotic metabolites detected at parts per million concentrations in retina of pigs - A new matrix for enhanced monitoring of nitrofuran abuse. Analyst 130: 466-468. [Medline] [CrossRef]

12. Cooper, K. M., Mulder, P. P. J., van Rhijn, J. A., Kovacsics, L., McCracken, R. J., Young, P. B. and Kennedy, D. G. 2005 b. Depletion of four nitrofuran antibiotics and their tissue-bound metabolites in porcine tissues and determination using LC-MS/ MS and HPLC-UV. Food Addit. Contam. 22: 406-414. [Med- 
line] [CrossRef]

13. Cooper, K. M., Samsonova, J. V., Plumpton, L., Elliott, C. T. and Kennedy, D. G. 2007. Enzyme immunoassay for semicarbazide-The nitrofuran metabolite and food contaminant. Anal. Chim. Acta 592: 64-71. [Medline] [CrossRef]

14. Diblikova, I., Cooper, K. M., Kennedy, D. G. and Franek, M. 2005. Monoclonal antibody-based ELISA for the quantification of nitrofuran metabolite 3-amino-2-oxazolidinone in tissues using a simplified sample preparation. Anal. Chim. Acta 540: 285-292. [CrossRef]

15. Gao, A., Chen, Q., Cheng, Y., Lei, J. and Zeng, L. 2007. Preparation of monoclonal antibodies against a derivative of semicarbazide as a metabolic target of nitrofurazone. Anal. Chim. Acta 592: 58-63. [CrossRef]

16. Horne, E., Cadogan, A., O'Keeffe, M. and Hoogenboom, L. A. P. 1996. Analysis of protein-bound metabolites of furazolidone and furaltadone in pig liver by high-performance liquid chromatography and liquid chromatography mass spectrometry. Analyst 121: 1463-1468. [Medline] [CrossRef]

17. Jacobson, R. H. 1996. Principles of validation of diagnostic assays for infectious diseases. pp. 8-15. In: Manual of Standards for Diagnostic Tests and Vaccines, 3rd ed., Office International des Epizooties, Paris.

18. Lei, Y. C., Tsai, Y. F., Tai, Y. T., Lin, C. Y., Hsieh, K. H., Chang, T. H., Sheu, S. Y. and Kuo, T. F. 2008. Development and fast screening of salbutamol residues in swine serum by an enzyme- linked immunosorbent assay in Taiwan. J. Agric. Food Chem. 56: 5494-5499. [Medline] [CrossRef]

19. Leitner, A., Zollner, P. and Lindner, W. 2001. Determination of the metabolites of nitrofuran antibiotics in animal tissue by highperformance liquid chromatography-tandem mass spectrometry. J. Chromatogr. A 939: 49-58. [Medline] [CrossRef]

20. Liu, W., Zhao, C., Zhang, Y., Lu, S., Liu, J. and Xi, R. 2007. Preparation of polyclonal antibodies to a derivative of 1-aminohydantoin (AHD) and development of an indirect competitive ELISA for the detection of nitrofurantoin residue in water. $J$. Agric. Food Chem. 55: 6829-6834. [Medline] [CrossRef]

21. Nouws, J. F. M. and Laurensen, J. 1990. Postmortal degradation of furazolidone and furaltadone in edible tissues of calves. Vet. Q. 12: 56-59. [Medline] [CrossRef]

22. Pimpitak, U., Putong, S., Komolpis, K., Petsom, A. and Palaga, T. 2009. Development of a monoclonal antibody-based enzymelinked immunosorbent assay for detection of the furaltadone metabolite, AMOZ, in fortified shrimp samples. Food Chem. 116: 785-791. [CrossRef]

23. Van Koten-Vermeulen, J. E. M., Wouters, M. F. A. and Van Leeuwen, F. X. R. 1993. pp. 85 - 123. Report of the 40th Meeting of the Joint FAO/WHO Expert Committee on Food Additives (JECFA).

24. Vass, M., Diblikova, I., Cernoch, I. and Franek, M. 2008. ELISA for semicarbazide and its application for screening in food contamination. Anal. Chim. Acta 608: 86-94. [Medline] [CrossRef] 